\title{
Исследование профиля эффективного показателя преломления в самоорганизующихся наноструктурированных пленках ITO
}

\author{
(С) Л.К. Марков, А.С. Павлюченко, И.П. Смирнова, С.И. Павлов \\ Физико-технический институт им. А.Ф. Иофрфе Российской академии наук, \\ 194021 Санкт-Петербург, Россия \\ E-mail: I.markov@mail.ioffe.ru
}

(Получена 26 февраля 2018 г. Принята к печати 12 марта 2018 г.)

\begin{abstract}
Исследовались оптические характеристики и структурные особенности самоорганизующихся наноструктурированных пленок оксида индия и олова (ITO), нанесенных методом электронно-лучевого испарения на нагретые выше $400^{\circ} \mathrm{C}$ подложки. Оценки профилей распределения вещества и значения эффективного показателя преломления в исследуемых пленках были получены компьютерным моделированием среды, имеющей наиболее близкие к наблюдаемым в эксперименте спектральные зависимости коэффициентов пропускания и отражения света. Полученные результаты находятся в хорошем согласии с данными растровой электронной микроскопии для этих пленок и позволяют не только подтвердить градиентный характер таких покрытий, но и восстановить его некоторые особенности. Дальнейшее заращивание пустот в самоорганизующихся наноструктурированных пленках посредством нанесения дополнительного количества материала методом магнетронного распыления при комнатной температуре приводит к изменению в них профиля эффективного показателя преломления. Таким образом можно создавать прозрачные проводящие покрытия с профилем эффективного показателя преломления, настраиваемым под поставленные задачи. Настройка профиля показателя преломления в самоорганизованных пленках ITO приобретает особое значение для конструирования покрытий с заданными свойствами в силу ограниченного набора прозрачных проводящих материалов.
\end{abstract}

DOI: $10.21883 /$ FTP.2018.10.46466.8853

\section{1. Введение}

Прозрачный и одновременно проводящий материал оксид индия и олова (ITO) активно исследуется в последнее время в связи с его широкой востребованностью в различных областях техники. В зависимости от требований, выдвигаемых сферой его применения, могут быть получены пленки с различными свойствами. Если на первом этапе изучения и применения пленок ITO общим стремлением исследователей являлось достижение максимальной прозрачности при минимальном поверхностном сопротивлении пленки, то в дальнейшем все большее внимание стали привлекать вопросы создания структуры, предназначенной для изменения френелевского отражения на ее границах. Так, например, поскольку оксид индия и олова характеризуется относительно высоким показателем преломления, для эффективного вывода света из него и борьбы с явлением полного внутреннего отражения на границе пленки при выходе излучения в среду с меньшим значением показателя преломления хороший результат обеспечивает текстурирование поверхности пленки. Наибольшее освещение эти вопросы получили в статьях, посвященных выводу света из светодиодных кристаллов на основе $\mathrm{GaN}$, поскольку этот материал сам характеризуется высоким показателем преломления и большая часть генерируемого излучения оказывается запертой в кристалле, как в волноводе, затухая на каждом акте прохождения по нему, что соответственно существенно снижает квантовую эффективность светодиодов. Первоначальный подход к увеличению вывода света из пленки ITO в среду с меньшим показателем преломления заключался в создании микрорельефа на внешней границе пленки посредством маскирования различными способами и дальнейшего травления $[1,2]$.

Отдельное направление представляют собой попытки создания структурированных проводящих пленок на основе ITO, состоящих из нескольких слоев различного состава. Так, например, для модификации эффективного показателя преломления материала с сохранением его электрической проводимости в ITO добавлялись мелкодисперсные частицы $\mathrm{SiO}_{2}[3,4]$ или оксида сурьмы и олова (antimony-doped tin oxide, ATO) [5].

В последнее время все больше работ, исследующих пленки оксида индия и олова, рассматривают отличительную особенность этого материала, заключающуюся в том, что не только его оптические и электрические параметры определяются способом и технологическими параметрами нанесения, но одновременно и структурные особенности получаемых пленок существенным образом зависят от способов и режимов их получения. Подобный подход одним из первых был представлен в работах [6-8], где авторы предлагают использовать метод осаждения материала ITO при наклонном падении [9] для создания пленок с различными значениями показателя преломления. По мере развития и совершенствования технологии создания пленок ITO внимание исследователей все больше концентрируется на склонности материала при определенных условиях его нанесения формировать кристаллы вытянутой формы с образованием наноразмерных структур в виде „леса“ из 
„нанонитей“ (nanowires, nanowhisker, nanorods) [10-15]. Склонность к образованию кристаллов нитевидной формы объясняется возможностью при определенных условиях осуществить их рост по механизму пар-жидкостькристалл (ПЖК, vapor-liquid-solid или VLS в англоязычном варианте) $[16,17]$. В этом случае рост кристаллов идет по границе раздела кристалл-жидкость из капель расплава нанометрового размера. При этом в качестве катализатора процесса могут быть использованы различные наночастицы (например, золота, никеля или графита). Однако использование частиц катализатора для формирования прозрачных покрытий сопряжено с риском ухудшения их оптических характеристик. В то же время при определенных режимах нанесения материала оксида индия и олова существует возможность реализовать рост кристаллов нитевидной формы по механизму ПЖК без внешнего катализатора.

Применение этого подхода для формирования оптических проводящих покрытий с целью улучшения характеристик оптоэлектронных приборов показано в работах [18], где авторы наблюдали увеличение вывода света с поверхности светодиодного кристалла при замене гладкой пленки из оксида индия и олова на покрытие из нанонитей ITO, полученных с помощью катализа на полистироловых сферах нанометрового размера, и [19], где обсуждается увеличения квантового выхода светодиодов путем формирования древовидных структур ITO, сформированных методом осаждения при наклонном падении и при повышенных температурах подложки. В обоих случаях позитивный эффект, возникающий при применении структурированных пленок ITO, связывается авторами с градиентным характером показателя преломления пленки (показатель преломления такой пленки имеет градиент в направлении, перпендикулярном плоскости подложки). Более детальнее этот вопрос будет рассмотрен далее.

Дальнейшее совершенствование технологии получения прозрачных проводящих покрытий будет идти, по мнению авторов настоящей публикации, по пути создания многослойных композиций этого материала, позволяющих использовать структурные особенности материала, которые невозможно получить для однослойных пленок. Подтверждение этого подхода можно найти в работе [20], где авторы использовали многослойную пленку ITO, решая противоположную задачу получения покрытия с наименьшей шероховатостью для его использования в составе контакта лазера поверхностного излучения с вертикальным объемным резонатором (VCSEL).

Авторы настоящей работы наблюдали формирование самоорганизующихся наноструктурированных пленок ITO при нанесении материала на подложки, нагретые до температур $>400^{\circ} \mathrm{C}$, при использовании как метода электронно-лучевого испарения, так и магнетронного распыления [21]. При таких температурах за образование кристаллов вытянутой формы также отвечает механизм ПЖК. Подтверждением данного пред- положения служат затвердевшие шарообразные капли, расположенные на вершинах кристаллических нитей, которые видны на некоторых изображениях пленок, полученных с помощью растровой электронной микроскопии. В дальнейшем, в работе [22], был предложен оригинальный метод модификации свойств и структуры покрытия путем осаждения дополнительного количества этого же материала, но при других условиях. Сущность метода заключается в том, что на пленку, полученную на первой стадии ее формирования и состоящую из вытянутых нитевидных кристаллов, наносится дополнительный материал методом магнетронного распыления при более низкой температуре. При этом осаждение материала на второй стадии идет в основном таким образом, что происходит заращивание пустот в пленке. Следовательно, комбинацией методов вакуумного напыления при различных температурах подложки могут быть получены пленки ITO с различными структурными особенностями и соответственно с различными оптическими свойствами.

Как обсуждалось в [22], поскольку размеры структурных неоднородностей получаемых покрытий составляют, как правило, десятки нм, к оценке эффективного показателя преломления данной пленки можно подойти с помощью модели эффективной среды [23]. Оценки эффективного показателя преломления, сделанные в рамках геометрии Оделевского [24], приводят к сопоставимым с экспериментом результатам. Таким образом, получение материала с требуемым значением эффективного показателя преломления может быть достигнуто изменением соотношения масс вещества, осаждаемого на каждой из указанных выше стадий его нанесения.

В то же время в силу характера напыляемых на первой стадии пленок они, как правило, неоднородны в направлении, перпендикулярном плоскости подложки. Имеющийся профиль распределения плотности вещества в указанном направлении также приводит к возникновению профиля эффективного показателя преломления, что соответственно влияет на оптические свойства покрытия. В настоящей работе мы рассмотрим вопросы, связанные с характером распределения эффективного показателя преломления в таких самоорганизованных пленках ITO, а также его модификацию при заращивании пустот путем нанесения дополнительного количества материала согласно методу, предлагаемому в [22].

\section{2. Результаты эксперимента и их обсуждение}

В настоящей работе формирование пленок ITO, имеющих в составе вытянутые нитевидные кристаллы, проводилось методом электронно-лучевого испарения при нагреве подложки до температуры $450^{\circ} \mathrm{C}$ с последующим напуском в вакуумную камеру азота ОСЧ до давления, близкого к атмосферному ( 800 мбар), и дальнейшей выдержкой образца в атмосфере азота в течение 10 мин 
без выключения нагрева. Скорость осаждения материала составляла $\sim 10 \mathrm{Hм} /$ мин. Технология нанесения таких пленок детально описана в работе [22]. Поскольку контроль толщины пленок проводился в процессе их нанесения с помощью кварцевого датчика, измеряющего массу наносимого материала, а калибровка датчика осуществлялась на сплошном плотноупакованном материале, реальная толщина пленок, содержащих пустоты, отличалась от измеренной в процессе нанесения. Как правило, общая толщина наносимых данным методом пленок превосходила толщину плотноупакованных пленок в несколько раз. В дальнейшем мы будем для простоты изложения количество материала ITO, наносимое в одном процессе напыления пленки, характеризовать толщиной пленки без пустот, содержащей такое же количество материала. В этом случае будет говориться о количестве материала „в эквиваленте плотной пленки“. Таким образом, фраза: „была нанесена пленка толщиной $X$ нм в эквиваленте плотной пленки“, означает, что на подложку было осаждено такое же количество материала, как при нанесении плотноупакованной пленки толщиной $X$ нм.

В данной работе осаждение материала методом магнетронного напыления проводилось со скоростью 6-8 нм/мин при комнатной температуре с последующим отжигом образца также при $450^{\circ} \mathrm{C}$ в атмосфере азоте при давлении $\sim 800$ мбар в течение 10 мин. Детали этой технологии также освещены в [22].

Изучение оптических характеристик пленок на стекле проводилось на тестовых образцах, представляющих собой покровные стекла толщиной 0.17 мм, на одну сторону которых наносились исследуемые пленки. Спектры пропускания и отражения образцов исследовались на спектрорадиометре Cary 430 производства фирмы Agilent. Излучение падало на образец со стороны пленки нормально к его поверхности.

Для изучения структурных особенностей пленок, полученных методом электронно-лучевого испарения, был изготовлен ряд образцов, представляющих собой пленки ITO различной толщины на различных подложках, не взаимодействующих c In или Sn при повышенных температурах: стекло, кварц, лейкосапфир, гетероструктуры AlGaInN на лейкосапфировой подложке, кремний, нержавеющая сталь. Согласно нашим наблюдениям, все полученные пленки ITO имеют схожую структуру: они состоят из зародышевого слоя, на котором происходит образование и рост кристаллов вытянутой, нитевидной формы толщиной $\sim 20$ нм. На рис. 1 приведены изображения, полученные с помощью растрового электронного микроскопа, пленок ITO толщиной 50, 120 и 170 нм в эквиваленте плотной пленки, на стеклянной подложке.

Как видно из рис. 1, пленки, полученные таким методом, характеризуются выраженным градиентом плотности вещества в вертикальном направлении: плотный зародышевый слой сменяется слоем, состоящим из нитевидных кристаллов различной высоты. При этом чем тоньше пленка, тем выше ее усредненная удельная
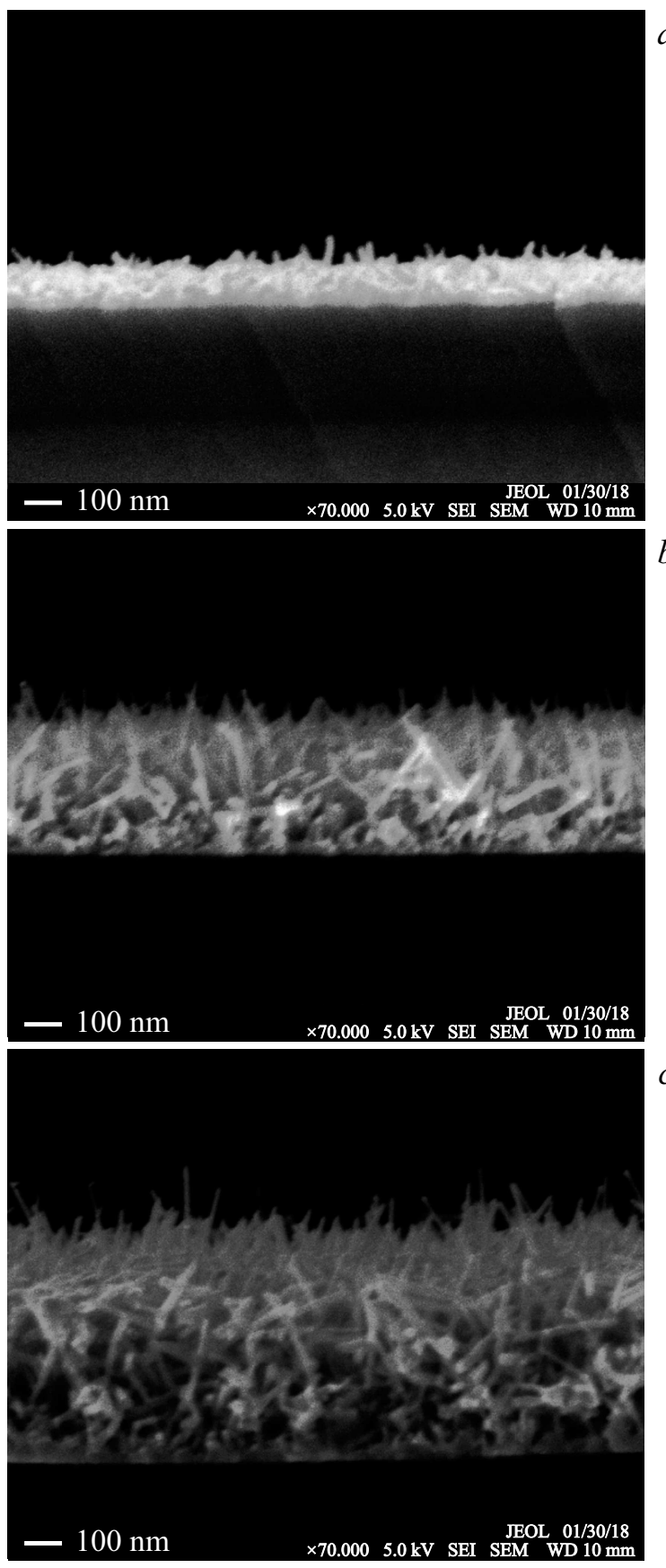

Рис. 1. РЭМ-изображения пленок ITО толщиной в эквиваленте плотной пленки $50(a), 120(b)$ и 170 нм $(c)$.

плотность за счет увеличения доли более плотного зародышевого слоя в общей массе материала пленки. Как следует из рисунка, после образования зародышевого слоя основной рост пленки идет по механизму ПЖК. Соответственно, поскольку в пленках наблюдается градиент плотности вещества в направлении, перпендикулярном плоскости подложки, эффективный показатель преломления такой пленки также должен иметь градиент в этом же направлении. Такие, градиентные, покрытия [25-30] эффективно применяются для борьбы 
с френелевским отражением на границе двух сред в случае, когда излучение не является монохроматическим или падает на границу под разными углами. Дело в том, что стандартные просветляющие покрытия позволяют воспользоваться преимуществом конструктивной интерференции для повышения коэффициента пропускания света в условиях монохроматического излучения при распространении его в определенном направлении. В то же время в большинстве приборов свет может распространяться в различных направлениях или же не являться монохроматическим. Например, в светодиодных кристаллах излучение, возникающее в активном слое в результате процессов рекомбинации носителей заряда, может распространяться во всех направлениях с одинаковой вероятностью. Как мы упоминали выше, в работах $[18,19]$ сообщалось о значительном увеличении квантового выхода светодиодов при использовании в качестве прозрачных проводящих контактов самоорганизующихся структурированных пленок ITO, содержащих вытянутые кристаллы, полученные с помощью катализа на полистироловых сферах нанометрового размера [18] и осаждением при наклонном падении и при повышенных температурах подложки [19]. Одним из эффективных вариантов просветляющего градиентного покрытия является пленка, в которой показатель преломления плавно меняется от одного до другого значения показателей преломления ограничивающих пленку сред. Способ создания градиентного покрытия из материала оксида индия и олова с использованием многократного осаждения материала под разными углами при наклонном падении описывается в [8]. В работе [31] авторы также наблюдали подавление френелевского отражения с помощью схожих с рассматриваемыми в настоящей работе по своей структуре градиентных покрытий, полученных методом молекулярно-лучевой эпитаксии.

Стоит отметить, что самоорганизующиеся градиентные покрытия, получаемые нами в результате нанесения материала при повышенных температурах подложки (согласно приведенной выше технологии), наиболее просты для реализации с технологической точки зрения, а возможность последующего заращивания пор в материале позволяет оптимизировать свойства пленки.

Характер взаимодействия света с образцами, представляющими собой пленки ITO, нанесенные методом электронно-лучевого испарения по вышеописанной технологии на стеклянные подложки, показан на примере серии образцов с пленками толщиной 50, 100 и 120 нм (рис. 2). Как видим, спектральные характеристики образцов не обнаруживают интерференционных особенностей, что служит подтверждением градиентного характера распределения показателя преломления в структуре пленки. При этом поверхность самой тонкой пленки, имеющая, как мы видим из рис. 1, менее развитую структуру нитевидных кристаллов, характеризуется большим отражением от нее, что соответственно приводит к меньшему пропусканию образца в видимом диапазоне длин волн излучения. В то же время по мере роста толщины

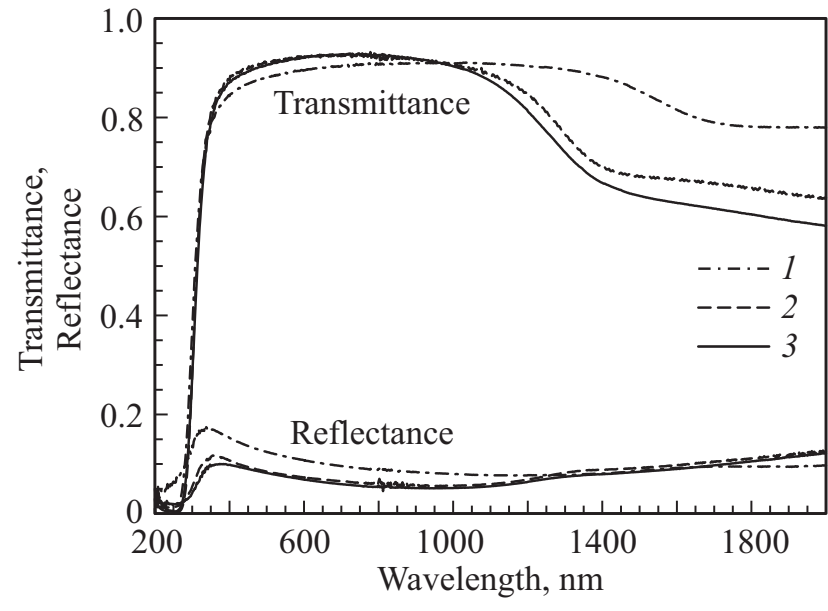

Рис. 2. Спектральные зависимости коэффициентов пропускания и отражения пленок ITO с толщиной в эквиваленте плотной пленки 50 (1), 100 (2), 120 нм (3).

пленки растет поглощение излучения в инфракрасном (ИК) диапазоне, а отражение становится минимальным. Как видно из рисунка, спектральные характеристики образцов толщиной 100 и 120 нм практически одинаковы и различаются лишь поглощением в ИК диапазоне с длинами волн > 1000 нм. Поглощение наноструктурированных объектов в этой области спектра может быть связано с резонансными эффектами на элементах наноструктуры согласно работам [32,33]. Поскольку в составе рассматриваемых нами самоорганизующихся покрытий имеются нитевидные кристаллы различной длины и их ориентация не строго упорядочена, поглощение имеет широкополосный характер в этой области спектра.

Как мы уже упоминали выше, распределение материала и, как следствие, эффективного показателя преломления в самоорганизующихся градиентных покрытиях, полученных нанесением материала ITO методом электронно-лучевого испарения на горячую подложку, имеет сложный характер. Для его оценки и понимания того, насколько профиль показателя преломления покрытия влияет на оптические характеристики образца, мы использовали следующий модельный эксперимент.

Для расчета спектров пропускания пленки ITO моделировались последовательными слоями, характеризуемыми различной плотностью материала. Эффективная диэлектрическая проницаемость слоев определялась из объемного коэффициента заполнения в предположении нормально ориентированных пустот [24]. Такое предположение согласуется со структурой материала, наблюдаемой на РЭМ-изображениях пленок. Расчет пропускания выполнялся методом матриц переноса [34] для многослойной пленки в сочетании с френелевским отражением задней границы подложки. Таким образом, модель пленки задавалась сочетанием дисперсии объемного материала, которая определялась функцией комплексного 
показателя преломления от длины волны $n(\lambda)-i \cdot k(\lambda)$, и профиля коэффициента заполнения пленки.

Для определения параметров наносимого материала ITO, зависимостей $n(\lambda)$ и $k(\lambda)$ был изготовлен образец, представляющий собой плотную пленку, полученную методом магнетронного распыления. Процесс проводился при комнатной температуре с последующим отжигом по приведенной выше технологии, толщина пленки составила 170 нм. Данная пленка не содержит пустот и имеет наиболее ровную поверхность, что упрощает построение ее модели и позволяет определять параметры среды с наибольшей достоверностью. На основании полученных спектров пропускания и отражения образца были определены характеристики наносимого нами в экспериментах материала ITO. Далее для пленки на стеклянной подложке моделировались различные варианты распределения эффективного показателя преломления в пленке по оси, перпендикулярной плоскости подложки. Рассматривались покрытия с массовым содержанием вещества, соответствующим плотной пленке толщиной 120 и 440 нм (реальная толщина покрытия по данным РЭМ в соответствии с рис. $1, b)$. Методом последовательных приближений находилось такое распределение вещества в пленке, которое бы обеспечило лучшее соответствие расчетных спектров пропускания и отражения наблюдаемым в эксперименте (кривые 2 на рис. 2). Оптимизация проводилась в диапазоне длин волн < 1000 нм, где, как мы обсуждали выше, эффекты поглощения на элементах наноструктуры не играют существенной роли.

На рис. 3 приведены смоделированные спектры пропускания и отражения для этой пленки в сравнении с экспериментальными данными для нее (рис. 3, $a$ ), а также расчетный профиль распределения вещества в структуре исследуемой пленки, полученный при прохождении света через модельный образец с данной пленкой (рис. $3, b$ ). На рис. $3, b$ приведен профиль объемного коэффициента заполнения последовательности слоев ITO, обеспечивающий наилучшее соответствие расчетных спектров пропускания и отражения экспериментальным данным. Профиль эффективного показателя преломления в пленке полностью определяется распределением материала в ней, однако в силу имеющейся дисперсии показателя преломления вещества сам профиль показателя преломления будет различным для разных длин волн. Для примера на рис. 3, $b$ также приведен профиль эффективного показателя преломления в исследуемой пленке для длины волны излучения 460 нм (наиболее распространенное значение длины волны собственного излучения светодиодов).

Сравнение расчетных спектральных зависимостей с данными эксперимента показывает их хорошее согласие. Одновременно полученное распределение вещества в структуре исследуемой пленки достаточно хорошо согласуется с данными растровой электронной микроскопии. Согласно расчету (рис. $3, b$ ), по мере удаления от подложки достаточно плотная среда (зародышевый
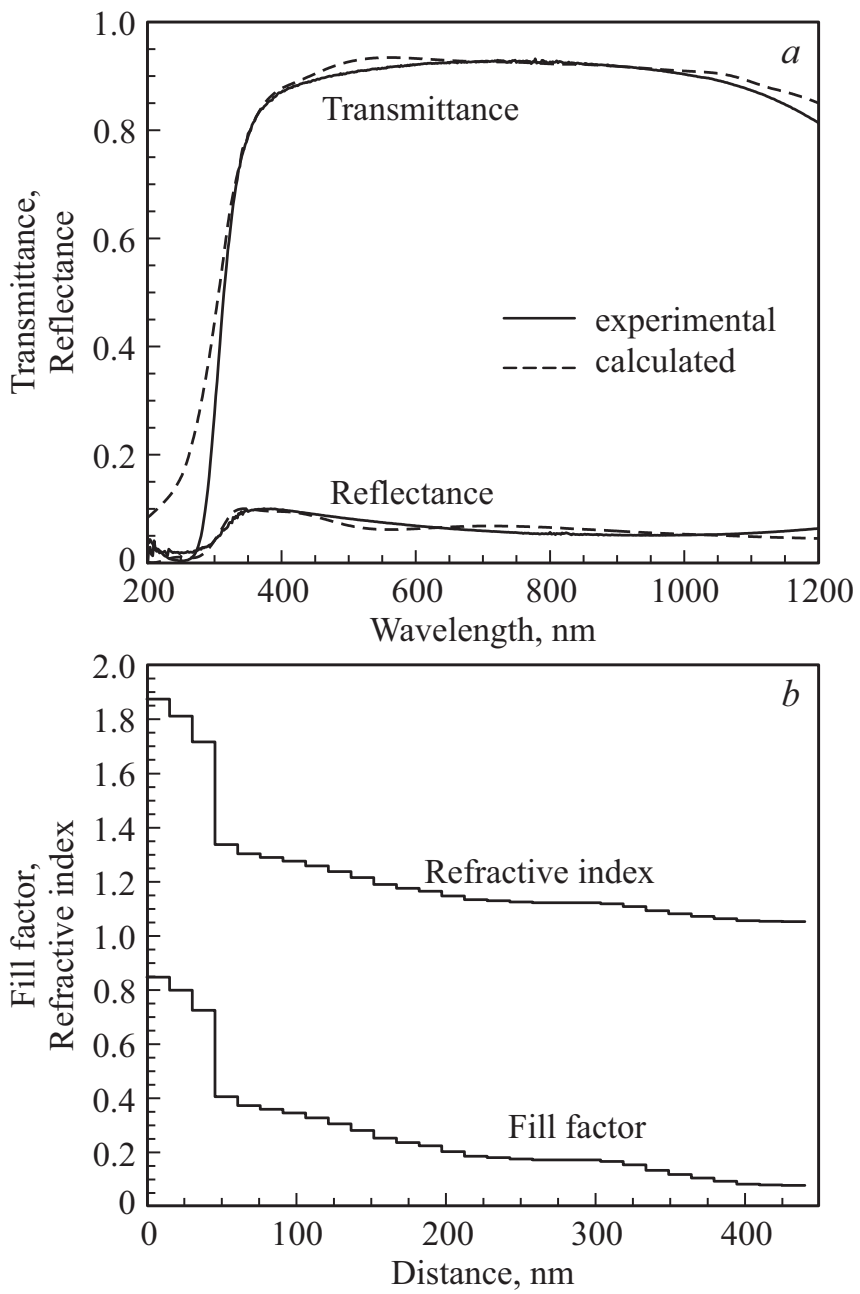

Рис. 3. Характеристики пленки ITO толщиной в эквиваленте плотной пленки 120 нм, полученной методом электроннолучевого испарения на горячую подложку: $a-$ расчетные и экспериментальные спектральные зависимости коэффициентов пропускания и отражения образца; $b-$ расчетные профили распределения вещества и эффективного показателя преломления в пленке для длины волны излучения 460 нм.

слой), ограниченная толщиной $\sim 45$ нм, сменяется менее плотной средой с постепенно убывающей плотностью материала (нитевидные кристаллы разной длины). Интересно, что сам зародышевый слой имеет градиентный характер плотности вещества в нем и даже в непосредственной близости от подложки его плотность не достигает максимального значения плотной пленки. По всей видимости, такой характер распределения вещества в зародышевом слое определяется наблюдаемыми в его структуре зернами различного размера.

Как обсуждалось выше, при дальнейшем нанесении на структурированные образцы материала оксида индия и олова методом магнетронного распыления при комнатной температуре нитевидные кристаллы начинают покрываться дополнительным слоем ITO, формируя перевернутые конусообразные структуры со сферическим 

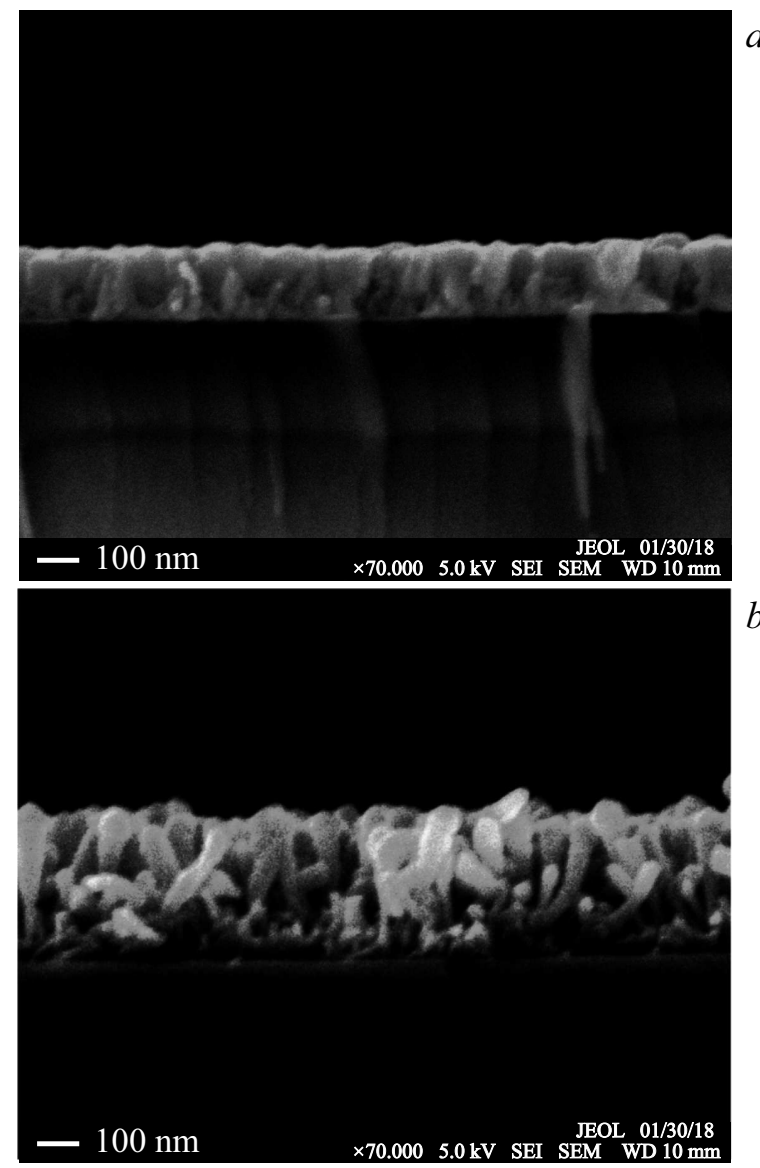

Рис. 4. РЭМ-изображения пленок ITО с одинаковой массой нанесенного материала, полученных методом магнетронного распыления $(a)$ и комбинированным методом $(b)$.

основанием [22]. При этом происходит как заполнение имеющихся в пленке пустот, так и изменение характера распределения материала по оси, перпендикулярной плоскости подложки.

Для оценки влияния структуры материала на коэффициент пропускания образцов на стеклянные подложки были нанесены следующие пленки ITO по описанной выше технологии:

- пленка электронно-лучевого испарения толщиной 170 нм в эквиваленте плотной пленки, нанесенная на стеклянную подложку согласно описанной выше технологии (образец 1); РЭМ-изображение этого образца приведено на рис. 1, $c$;

- комбинированная пленка, полученная методом электронно-лучевого испарения толщиной 100 нм в эквиваленте плотной пленки согласно описанной выше технологии, с дальнейшим заращиванием пор нанесением слоя материала методом магнетронного распыления при комнатной температуре толщиной 70 нм в эквиваленте плотной пленки (образец 2): РЭМ-изображение этого образца приведено на рис. $4, b$;

- пленка, полученная методом магнетронного распыления толщиной 170 нм: процесс проводился при ком- натной температуре с последующим отжигом по приведенной выше технологии (образец 3); РЭМ-изображение этого образца приведено на рис. 4, $a$.

Все образцы характеризуются одной массой нанесенного материала, что позволяет в первом приближении считать поглощение света при его прохождении через образцы одинаковым для всех образцов. На рис. 5 приведены спектры пропускания всех изготовленных образцов в диапазоне длин волн, не превышающих 1000 нм, где, как обсуждалось выше, практически отсутствуют резонансные эффекты на элементах наноструктуры. Как видно из рисунка, для стеклянных подложек самоорганизующееся покрытие, возникающее при нанесении материала ITO методом электронно-лучевого испарения на горячую подложку (образец 1), обладает преимуществом перед всеми изготовленными образцами с точки зрения прохождения света через образец. В видимом диапазоне длин волн пропускание образцов 2 и 3 может конкурировать с пропусканием образца 1 лишь при условии конструктивной интерференции, что означает существенно меньшее интегральное пропускание немонохроматического и (или) распространяющегося в разных направлениях света.

Согласно данным рис. 5, форма спектральной зависимости коэффициента пропускания образцов с пленками, сформированными комбинированным методом напыления и электронно-лучевым испарением, принципиально различается. Образец с пленкой комбинированного напыления обнаруживает выраженные интерференционные особенности в спектрах пропускания. Поскольку пленка комбинированного напыления получена из пленки электронно-лучевого испарения, не обладающей интерференционными особенностями спектров пропускания, изменение оптических характеристик пленки вызвано перераспределением профиля плотности вещества

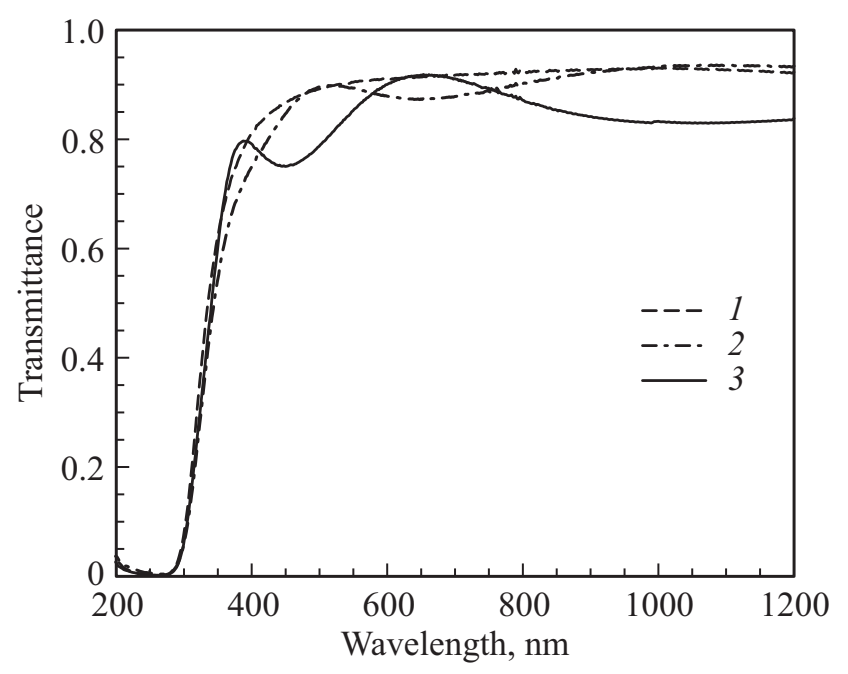

Рис. 5. Спектры пропускания образцов с пленками ITO одинаковой массы, полученными разными методами: 1 - электронно-лучевое испарение на горячую подложку, 2 - комбинированный метод, 3 - магнетронное распыление. 
в структуре пленки по мере заращивания пустот в ней на второй стадии формирования. Несмотря на то что обе исследуемые пленки имеют в своей структуре зародышевый слой с произрастающими из него кристаллами вытянутой формы, ориентированными преимущественно в перпендикулярном плоскости подложки направлении, форма кристаллов (см. рис. 1, с и 4,b) и, следовательно, распределение плотности материала и эффективного показателя преломления в них различны.

Для оценки профиля эффективного показателя преломления в пленке, полученной комбинированным методом (образец 2), было также проведено компьютерное моделирование согласно рассмотренному методу. Моделировалось покрытие толщиной 360 нм (по данным РЭМ, приведенным на рис. 4,b) с массовым содержанием вещества, соответствующим плотной пленке толщиной 170 нм. На рис. 6, а приведен смоделированный спектр пропускания образца на стеклянной подложке с такой пленкой в сравнении с экспериментальными данными. Расчетные профили распределения вещества и эффективного показателя преломления (для длины волны излучения 460 нм) в исследуемой пленке, полученной комбинированным методом, изображены на рис. $6, b$.

Как видим из сопоставления рис. $3, b$ и $6, b$, пленка, полученная комбинированным способом, характеризуется меньшим контрастом показателя преломления между областью зародышевого слоя и областью пониженного показателя преломления (нитевидных кристаллов с дополнительно осажденным материалом на них). При этом градиент показателя преломления во второй области значительно меньше, чем в пленке без дополнительного нанесения материала, а внешняя граница пленки имеет больший контраст показателя преломления с окружающей средой (воздухом в нашем эксперименте).

Таким образом, комбинированные пленки, полученные заращиванием пустот в самоорганизованных градиентных покрытиях, обладают другим характером распределения материала и, следовательно, профиля эффективного показателя преломления, что выражается в существенном отличии оптических характеристик. Данный факт имеет не только теоретическое значение, поскольку позволяет варьировать свойства формируемых покрытий, настраивая их требуемым образом. Как мы отмечали выше, структура самоорганизующихся покрытий зависит от режимов их получения, среди которых температура подложки, скорость, время, метод их нанесения и т.д. Учитывая тот факт, что можно варьировать параметры процесса нанесения материала и на второй стадии нанесения материала, при заращивании пустот, возникает возможность модифицировать профиль эффективного показателя преломления пленки. Таким образом можно создавать прозрачные проводящие покрытия с настраиваемым под поставленные задачи профилем эффективного показателя преломления. Если при создании непроводящих пленок задача создания сложных покрытий с нужными параметрами дизайна решается довольно просто последовательным нанесением
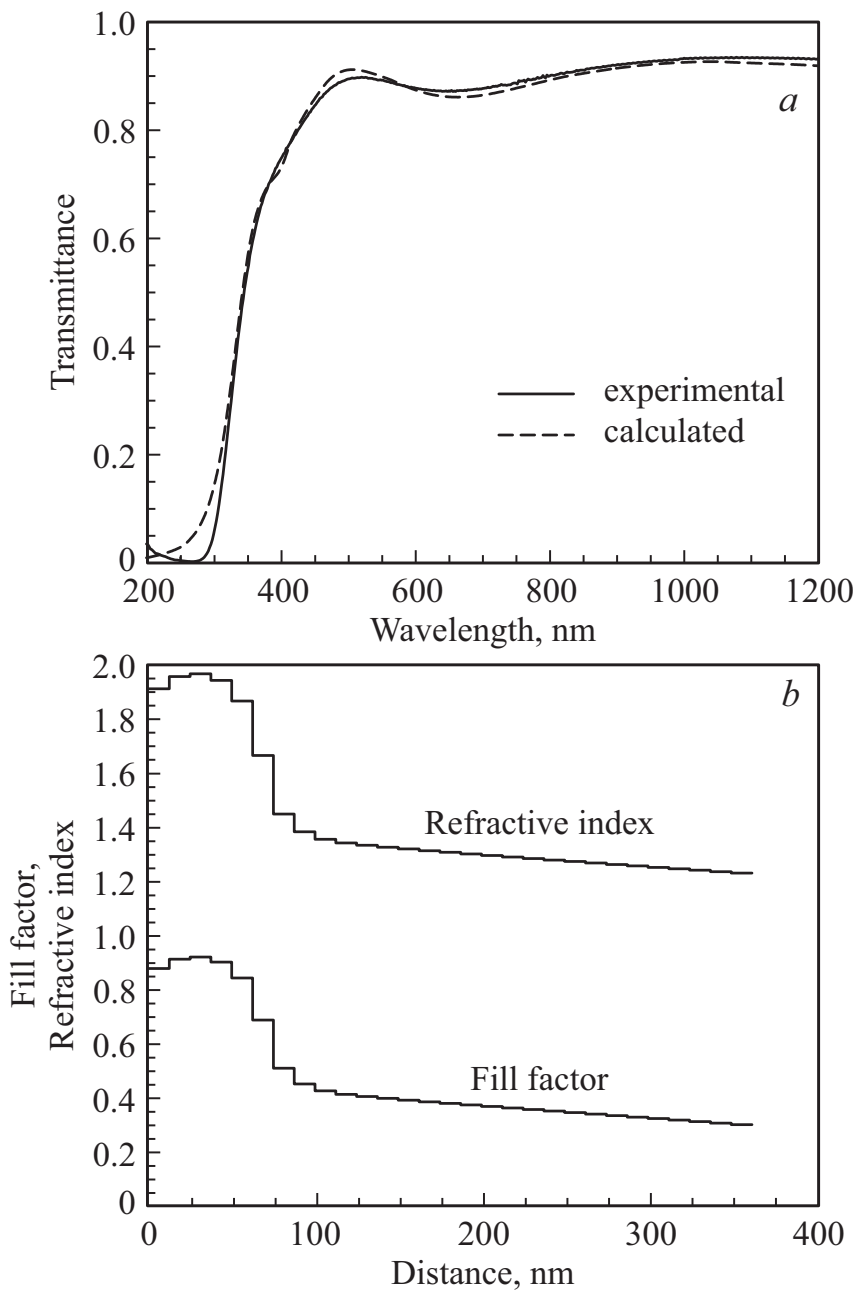

Рис. 6. Характеристики пленки ITO толщиной в эквиваленте плотной пленки 170 нм, полученной комбинированным методом (образец 2): $a-$ расчетная и экспериментальная спектральные зависимости коэффициента пропускания образцов; $b$ - расчетные профили распределения вещества и эффективного показателя преломления в пленке для длины волны излучения 460 нм.

разных материалов благодаря широкой палитре материалов с разным значением показателя преломления, то в случае прозрачных проводящих покрытий такая возможность отсутствует. Именно поэтому настройка профиля показателя преломления в самоорганизованных пленках ITO приобретает особое значение.

Несмотря на то что, как видно из рис. 5, для образцов на стеклянной подложке самоорганизующееся покрытие, полученное методом электронно-лучевого испарения на горячую подложку, в широком диапазоне длин волн обеспечивает более высокое пропускание образца при выводе излучения в среду с показателем преломления, равным 1, метод создания комбинированных пленок может быть востребован при выводе излучения в среды с другими показателями преломления, поскольку, как мы видели выше, позволяет приблизить эффективный 
показатель преломления покрытия на внешней границе к показателю преломления среды. Кроме того, как показали наши эксперименты, для подложек с другим значением показателя преломления использование комбинированных пленок может обеспечить лучшие результаты даже при выводе света на воздух. Эти исследования мы планируем опубликовать в ближайшее время.

\section{3. Заключение}

Таким образом, компьютерное моделирование процессов распространения света в образцах с наноструктурированными тонкими пленками оксида индия и олова позволяет оценить наиболее вероятные профили распределения вещества и значения эффективного показателя преломления в них. Так, моделирование среды, имеющей наиболее близкие к наблюдаемым в эксперименте для самоорганизующихся пленок ITO спектральные зависимости коэффициентов пропускания и отражения, позволяет подтвердить не только градиентный характер таких покрытий, но и восстановить некоторые его особенности. Полученные результаты находятся в хорошем согласии с данными растровой электронной микроскопии для этих пленок. Предлагаемый нами комбинированный метод получения пленок ITO, заключающийся в заращивании пустот в самоорганизующихся наноструктурированных пленках посредством нанесения дополнительного количества материала на следующей стадии формирования пленки, приводит к изменению профиля эффективного показателя преломления в пленке. Данное обстоятельство может быть использовано для создания пленок с требуемыми свойствами.

При выполнении настоящей работы привлекалось оборудование, предоставляемое ЦКП „Элементная база радиофотоники и наноэлектроники: технология, диагностика, метрология“ (НТЦ микроэлектроники РАН).

\section{Список литературы}

[1] R. H. Horng, C.C. Yang, J.Y. Wu, S.H. Huang, C.E. Lee, D.S. Wuu. Appl. Phys. Lett., 86, 221101 (2005).

[2] Y.C. Lee, C.E. Lee, T.C. Lu, H.C. Kuo, S.C. Wang. Semicond. Sci. Technol., 23, 045013 (2008).

[3] P.G. O’Brien, Y. Yang, A. Chutinan, P. Mahtani, K. Leong, D.P. Puzzo, L.D. Bonifacio, Chen-Wei Lin, G.A. Ozin, N.P. Kherani. Solar Energy Mater.\& Solar Cells, 102, 173 (2012).

[4] Joong-Yeon Cho, Kyeong-Jae Byeon, Heon Lee. Optics Lett., 36, 3203 (2011).

[5] P.G. O’Brien, D.P. Puzzo, A. Chutinan, L.D. Bonifacio, G.A. Ozin, N.P. Kherani. Adv. Mater., 22, 611 (2010).

[6] J.K. Kim, T. Gessmann, E.F. Schubert, J.-Q. Xi, Hong Luo Jaehee Cho, Cheolsoo Sone, Yongjo Park. Appl. Phys. Lett., 88, 013501 (2006).

[7] M.F. Schubert, J.-Q. Xi, J.K. Kim, E.F. Schubert. Appl. Phys. Lett., 90, 141115 (2007).
[8] Jong Kyu Kim, Sameer Chhajed, Martin F. Schubert, E. Fred Schubert, Arthur J. Fischer, Mary H. Crawford, Jaehee Cho, Hyunsoo Kim, Cheolsoo Sone. Adv. Mater., 20, 801 (2008).

[9] K. Robbie, L.J. Friedrich, S.K. Dew, T. Smy, M.J. Brett. J. Vac. Sci. Technol. A, 13, 1032 (1995).

[10] X.Y. Xue, Y.J. Chen, Y.G. Liu, S.L. Shi, Y.G. Wang, T.H. Wanga. Appl. Phys. Lett., 88, 201907 (2006).

[11] A.J. Chiquito, A.J.C. Lanfredi, E.R. Leite. J. Phys. D: Appl. Phys., 41, 045106 (2008).

[12] Hak Ki Yu, Wan Jae Dong, Gwan Ho Jung, Jong-Lam Lee. ACS Nano, 5, 8026 (2011).

[13] R.R. Kumar, V. Gaddam, K.N. Rao, K. Rajanna. Mater. Res. Express, 1, 035008 (2014).

[14] G. De O. Setti, D.P. de Jesus, E. Joanni. Mater. Res. Express, 3, 105021 (2016).

[15] A.L. Beaudry, R.T. Tucker, J.M. LaForge, M.T. Taschuk, M.J. Brett. Nanotechnology, 23, 105608 (2012).

[16] Hak Ki Yu, Jong-Lam Lee. Sci. Rep., 4, Article number: 6589 (2014).

[17] Gang Meng, Takeshi Yanagida, Kazuki Nagashima, Hideto Yoshida, Masaki Kanai, Annop Klamchuen, Fuwei Zhuge, Yong He, Sakon Rahong, Xiaodong Fang, Seiji Takeda, Tomoji Kawai. J. Am. Chem. Soc., 135, 7033 (2013).

[18] Zhina Gong, Qiang Li, Yufeng Li, Han Xiong, Hao Liu, Shuai Wang, Ye Zhang, Maofeng Guo, Feng Yun. Appl. Phys. Express, 9, 082102 (2016).

[19] Min Joo Park, Chan Ul Kim, Sung Bum Kang, Sang Hyuk Won, Joon Seop Kwak, Chil-Min Kim, Kyoung Jin Choi. Adv. Optical Mater., 5, 1600684 (2017).

[20] J.T. Leonard, D.A. Cohen, B.P. Yonkee, R.M. Farrell, S.P. DenBaars, J.S. Speck, S. Nakamura. J. Appl. Phys., 118, 145304 (2015).

[21] И.П. Смирнова, Л.К. Марков, А.С. Павлюченко, М.В. Кукушкин, С.И. Павлов. ФТП, 48, 61 (2014).

[22] Л.К. Марков, И.П. Смирнова, А.С. Павлюченко, М.В. Кукушкин, Д.А. Закгейм, С.И. Павлов. ФТП, 50, 1001 (2016).

[23] W. Cai, V. Shalaev. Optical Metamaterials: Fundamentals and Applications (Springer Science \& Business Media, 2009).

[24] В.И. Оделевский. ЖТФ, $21 Б$ (6), 678 (1951).

[25] J.W.S. Rayleigh. Proc. London Math. Soc., 11, 51 (1880).

[26] P.H. Berning. J. Optical Soc. America, 52 (4), 431 (1962).

[27] S. Chhajed, M.F. Schubert, J.K. Kim, E.F. Schubert. Appl. Phys. Lett., 93, 251108 (2008).

[28] A. Mahdjoub, L. Zighed. Thin Sol. Films, 478, 299 (2005).

[29] T. Aytug, A.R. Lupini, G.E. Jellison, P.C. Joshi, I.H. Ivanov, T. Liu, P. Wang, R. Menon, R.M. Trejo, E. LaraCurzio, S.R. Hunter, J.T. Simpson, M. Parans Paranthaman, D.K. Christen. J. Mater. Chem. C, 3, 5440 (2015).

[30] J.-Q. Xi, M.F. Schubert, J.K. Kim, E.F. Schubert, M. Chen, S.Y. Lin, W. Liu, J.A. Smart. Nature Photonics, 1, 176 (2007).

[31] C. O'Dwyer, C.M. Sotomayor Torres. Front. Phys., 1, 18 (2013).

[32] Shi Qiang Li, Peijun Guo, Lingxiao Zhang, Wei Zhou, T.W. Odom, T. Seideman, J.B. Ketterson, R.P.H. Chang. ACS Nano, 5, 9161 (2011).

[33] Peijun Guo, R.D. Schaller, L.E. Ocola, B.T. Diroll, J.B. Ketterson, R.P.H. Chang. Nature Commun., 7, Article number: 12892 (2016).

[34] М. Борн, Э. Вольф. Основы оптики (М., Наука, 1970).

Редактор Л.В. Шаронова 


\title{
Study of the effective refractive index profile in self-assembled nanostructured ITO films
}

\author{
L.K. Markov, A.S. Pavluchenko, I.P. Smirnova, \\ S.I. Pavlov \\ loffe Institute, \\ 194021 St. Petersburg, Russia
}

Abstract The optical characteristics and structural peculiarities of self-assembled nanostructured indium and tin oxide (ITO) films deposited by electron-beam evaporation on substrates heated above $400^{\circ} \mathrm{C}$ have been studied. The substance distributions and effective refractive indices in the obtained films have been determined by the computer simulations of a medium that is characterized by the spectral dependences of light transmission and reflection coefficients, which are most similar to the experimental dependences. The obtained results are in good agreement with the data of scanning electron microscopy for these films and allow one to confirm a gradient nature of these coatings as well as to restore some peculiarities of their nature. Further refilling of the voids in the self-assembled nanostructured films by magnetron sputtering deposition of additional material at the room temperature leads to a change in the effective refractive index profile in the films. Thus, the transparent conducting coatings with a effective refractive index profile adjusted for the desired tasks can be fabricated using this method. The adjustment of a refractive index profile in the selfassembled ITO films is of special importance for fabrication of the coatings with desired properties because of a lack of transparent conducting materials. 